\title{
Statistical Downscaling of Summer Temperature Extremes in Northern China
}

\author{
FAN Lijun*1,2 (范丽军), Deliang CHEN ${ }^{2}$, FU Congbin $^{1}$ (符淙斌), and YAN Zhongwei ${ }^{1}$ (严中伟) \\ ${ }^{1}$ Key Laboratory of Regional Climate-Environment Research for Temperate East Asia, \\ Institute of Atmospheric Physics, Chinese Academy of Science, Beijing 100029 \\ ${ }^{2}$ Department of Earth Sciences, University of Gothenburg, Gothenburg 40530, Sweden
}

(Received 20 March 2012; revised 27 August 2012; accepted 3 September 2012)

\begin{abstract}
Two approaches of statistical downscaling were applied to indices of temperature extremes based on percentiles of daily maximum and minimum temperature observations at Beijing station in summer during 1960-2008. One was to downscale daily maximum and minimum temperatures by using EOF analysis and stepwise linear regression at first, then to calculate the indices of extremes; the other was to directly downscale the percentile-based indices by using seasonal large-scale temperature and geo-potential height records. The cross-validation results showed that the latter approach has a better performance than the former. Then, the latter approach was applied to 48 meteorological stations in northern China. The crossvalidation results for all 48 stations showed close correlation between the percentile-based indices and the seasonal large-scale variables. Finally, future scenarios of indices of temperature extremes in northern China were projected by applying the statistical downscaling to Hadley Centre Coupled Model Version 3 (HadCM3) simulations under the Representative Concentration Pathways 4.5 (RCP 4.5) scenario of the Fifth Coupled Model Inter-comparison Project (CMIP5). The results showed that the 90th percentile of daily maximum temperatures will increase by about $1.5^{\circ} \mathrm{C}$, and the 10 th of daily minimum temperatures will increase by about $2^{\circ} \mathrm{C}$ during the period $2011-35$ relative to $1980-99$.
\end{abstract}

Key words: indices of temperature extremes, percentiles, statistical downscaling, future scenarios projection, northern China

Citation: Fan, L. J., D. L. Chen, C. B. Fu, and Z. W. Yan, 2013: Statistical downscaling of summer temperature extremes in northern China. Adv. Atmos. Sci., 30(4), 1085-1095, doi: 10.1007/s00376-0122057-0.

\section{Introduction}

Extreme weather and climate events have attracted increasing attention in the last 50 years owing to their large impact on human life, the environment, economy and society (IPCC, 2007). There is a common recognition that changes in the frequency and intensity of extremes events have a higher impact on the environment and human activities than changes in mean climate (Katz and Brown, 1992; Yan and Yang, 2000). The future climate is likely to be significantly different from that of the present because of global warming owing to increased greenhouse gas emissions from human activities. Thus, climate change scenarios are needed to assess the impacts of these changes on human activities and the environment. This has led to a growing demand for more reliable and finer spatial resolution scenarios of extreme climate events (e.g. Chen et al., 2008).

General Circulation Models (GCMs) are generally designed to simulate the present climate and project future climate. However, they are unable to present local- and regional-scale climate and their changes because of their coarse spatial resolutions. Therefore, there is a need to "translate" GCM simulations into much finer spatial resolution scenarios for climate change impact studies, known as "downscaling". Two major downscaling approaches are often used: dy-

\footnotetext{
*Corresponding author: FAN Lijun, fanlj@tea.ac.cn

(C) China National Committee for International Association of Meteorology and Atmospheric Sciences (IAMAS), Institute of Atmospheric Physics (IAP) and Science Press and Springer-Verlag Berlin Heidelberg 2013
} 
namic and statistical downscaling. Dynamic downscaling is a method of obtaining regional-scale information by using a regional climate model (RCM) driven by a GCM (e.g. Achberger et al., 2003), whereas statistical downscaling involves the application of statistical relationships between large- and local-scale climates, established by observations, to GCM outputs to construct future climate scenarios (Benestad et al., 2008). Its major advantages over dynamic downscaling are that it is simple and computationally efficient, and able to provide station-scale climatic variables from GCM outputs (Fan et al., 2005; Hanssen-Bauer et al., 2005; Wilks, 2010). A number of inter-comparison studies indicate that statistical downscaling methods and RCM-based methods have comparable skill over both daily and monthly timescales, at least for present climate conditions (Hellström et al., 2001; HanssenBauer et al., 2003).

Some studies of statistical downscaling of extreme climate events have been carried out (Coulibaly, 2004; Hundecha and Bardossy, 2008; Lee et al., 2011a, b). However, statistical downscaling of extreme events is still a relatively new area for climate change study, especially in China, where studies of statistical downscaling have focused mainly on mean climate (Hellström and Chen, 2003; Chen et al., 2006; Wetterhall et al., 2006; Fan et al., 2007; Zhao and Xu, 2008; Zhu et al., 2008; Fan, 2009, 2010; Liu et al., 2011).

Extreme climate events can be defined as events that occur with extraordinarily low frequency during a certain period of time (rarity), events with high magnitude (intensity) or duration, and events causing sizeable impacts, such as losses to human life and property (severity). In this study, the 90th and 10th percentiles were selected as indices of extreme events, i.e. those events that occurred less than the 10th percentile or larger than the 90th percentile of probability distributions of observed daily variables were defined as extreme events, which is a widely applied approach (e.g. IPCC, 2007). There were two reasons for this choice. First of all, they are more commonly used in previous studies for the analysis of extreme climate events since they are comparable and transferable among different climatic variables in different regions, compared to a fixed threshold. Secondly, if more extreme indices, such as the 1st and 99th percentiles of daily variables, are used, it may be difficult to obtain statistically stable and reliable results owing to the relatively short duration of the observations (Jones et al., 1999; Yan et al., 2002).

A commonly used approach of constructing seasonally extreme indices is that the daily results of statistical downscaling are used to calculate extreme temperature indices on a seasonal basis. However, this approach has some shortcomings that are worth mentioning. Firstly, statistical downscaling on a daily scale often requires daily GCM outputs, which are not always available [for example, the fifth coupled model inter-comparison project (CMIP5) websites do not provide daily-scale Hadley Centre Coupled Model Version 3 (HadCM3) scenarios]. Secondly, daily simulations are generally less reliable than those on a monthly scale. Thirdly, since temperature-related indices on a monthly or seasonal scale generally follow a normal distribution, a linear regression model can be directly used for the downscaling, while a more complex method needs to be considered for downscaling daily values because of the non-normal distribution of many daily values.

This study attempts to avoid the problems of directly downscaling daily temperature time series by establishing statistical downscaling models between the seasonal means of large-scale climatic predictors and extreme temperature indices. To prove the usefulness of this approach, a station in northern China was used first to compare the performance of the two options for the downscaling mentioned above. Then, the proposed approach was applied to 48 stations in northern China to simulate historical and future climate using a GCM output.

\section{Extreme temperature indices and data used}

Four temperature-related indices were selected as predictants in statistical downscaling procedures involving summer average (Tmaxave) of daily maximum temperature (Tmax), summer average (Tminave) of daily minimum temperature (Tmin), the 90th percentile of summer daily maximum temperature (Tmax90p), and the 10th percentile of summer daily minimum temperature (Tmin10p). The Tmax and Tmin data were obtained from homogenized historical data for China (Li and Yan, 2009). Summer average values (Tmaxave, Tminave), percentiles (Tmax90p, Tmin10p) and standard deviations of Tmax and Tmin (Tmaxsd and Tminsd) were calculated by 92 daily values for each summer during 1960-2008.

Northern China (Hebei, Shanxi, parts of Inner Mongolia, Beijing, and Tianjin) was selected as the target region, mainly because a significant warming and aridification trend has been found there during the past 50 years. The 48 meteorological stations selected in northern China are shown in Fig. 1.

In general, the choice of predictor variables and predictor domains (the location and dimensions of the large-scale predictor fields) is one of the most important steps in the development of statistical downscal- 


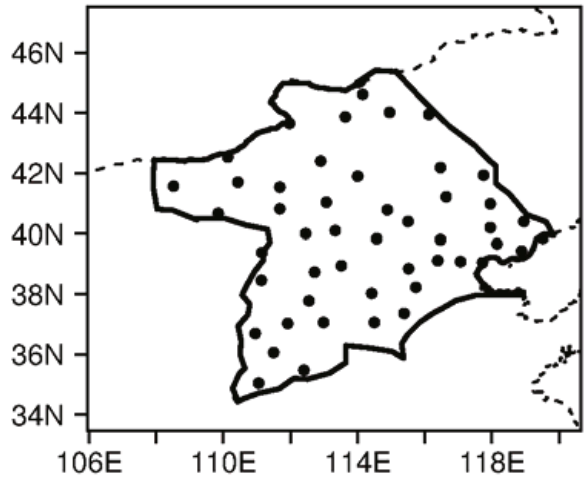

Fig. 1. Research area and locations of the 48 meteorological stations (solid dots).

ing models (Benestad, 2001). In statistically downscaling daily temperature in Europe, Huth (2002) reported that the best performance is achieved if one circulation field and one temperature field are used as predictors. Based on our previous experiences with downscaling monthly temperatures in northern China (Fan et al., 2007, 2011), the geo-potential height field (H850) and temperature field (T850) at $850 \mathrm{hPa}$ were selected as predictor variables and the area covering $\left(30^{\circ}-50^{\circ} \mathrm{N}, 100^{\circ}-130^{\circ} \mathrm{E}\right)$ was chosen as the predictor domain. Daily and monthly NCEP-NCAR (National Centers for Environmental PredictionNational Center for Atmospheric Research) Reanalysis data with a resolution of $2.5^{\circ} \times 2.5^{\circ}$ (Kalnay et al., 1996) for the summers during 1960-2008 were used as the observation of large-scale climate data, which were provided by the NOAA/Earth System Research Laboratory (ESRL)/Physical Sciences Division (PSD), Boulder, Colorado, USA, from their web site (http://www.esrl.noaa.gov/psd/data/gridded/data.ncep.reanalysis.html).

The GCM model used was the UK Met Office HadCM3, with a longitude-latitude grid resolution of $3.75^{\circ} \times 2.5^{\circ}$ and 19 hybrid vertical levels (Gordon et al., 2000; Pope et al., 2000).

A number of new emission scenarios called Representative Concentration Pathways (RCPs) have been introduced by the IPCC to drive climate model simulations. These RCPs have replaced the previous emission scenarios from the Special Report on Emissions Scenarios (SRES). The four RCPs, including RCP8.5, RCP6.0, RCP 4.5 and RCP2.6, are defined according to radiative forcing levels and pathway shapes. Among them, RCP4.5 is an intermedia-low pathway and a stabilization scenario in which radiative forcing is stabilized at approximately $4.5 \mathrm{~W} \mathrm{~m}^{-2}$ (approximately 650 ppm $\mathrm{CO}_{2}$-equavalent) after 2100 without ever exceeding that value (Moss et al., 2008, 2010). The RCP4.5 scenario is also a cost-minimizing pathway. It assumes that all nations of the world undertake emissions mitigation simultaneously and effectively (Thomson et al., 2011). Here, the historical (1960-2005) and RCP4.5 (2006-35) simulations by HadCM3 were adopted to downscale the indices of temperature extremes, based on CMIP5 (Taylor et al., 2009) from the website (http://badc.nerc.ac.uk/browse/badc/cmip5/).

\section{Statistical downscaling models}

This paper presents two approaches to the statistical downscaling of extreme temperature indices: one is to downscale daily Tmax and Tmin first, then to calculate the four indices of summer extreme temperature (DS1); the other is to directly downscale the four extreme temperature indices by using seasonally large-scale predictor variables (DS2).

Both downscaling approaches described above involve EOF analysis and stepwise liner regression analysis (von Storch and Zwiers, 1999). First, predictors of both H850 and T850 on the monthly or daily scale from NCEP-NCAR Reanalysis data were standardized with respect to their means and standard deviation during 1980-99. Then, these standardized fields were spatially combined into one new field $(H+T)$. For example, $H+T$ at grid $n$ and a given time $(t)$ can be described in terms of a vector $\boldsymbol{X}(t)=\left[x_{1}, x_{2}, \ldots, x_{n}\right]$ and H850 and T850 can be represented by two vectors, $\boldsymbol{Y}$ and $\boldsymbol{Z}$, of length $m$ respectively. Thus, the information on H850 and T850 can be combined by combining two vectors: $\boldsymbol{X}(t)=[\boldsymbol{Y}(t), \boldsymbol{Z}(t)]=$ $\left[y_{1}, y_{2}, \ldots y_{m}, z_{1}, z_{2}, \ldots z_{m}\right]$. The new field $(H+T)$ had the number of grids being equal to the sum of those for H850 and T850 without any alteration in time dimension. Next, $H+T$ was decomposed using EOF analysis into two parts: EOFs and principal components (PCs). The EOFs of $H+T$ were used to find the coupled patterns of H850 and T850 and their corresponding PCs represent their time-varying characteristics (Bretherton et al., 1992; Fan, 2010; Fan et al., 2011). Finally the first ten PCs of $H+T$ and observational data at each station were fed into stepwise linear regression to establish an optimum statistical downscaling model using the Akaike Information Criterion (AIC) (Chambers and Hastie, 1992) in a stepwise algorithm for each station and each index. For DS1, daily H850 and T850 datasets from the NCEP-NCAR Reanalysis data and historical daily Tmax and Tmin data at each station were used, whereas for DS2 summer means of monthly H850 and T850 datasets and the four extreme temperature indices calculated by daily Tmax and Tmin were used.

In order to make full use of the limited histori- 
cal observational data, the performances of the two statistical downscaling approaches were validated using the cross-validation method. The station at Beijing was taken as an example to compare the model skill between DS1 and DS2. Cross-validation procedures were as follows. Firstly, the first year (1960) was taken for prediction, while the years from 19612008 were used to construct the statistical downscaling models by adopting the downscaling processes described above. For DS1, daily Tmax and Tmin for 1960 were predicted by the models established during 1961-2008, and then used to calculate the four extreme temperature indices; while for DS2, extreme temperature indices for 1960 were downscaled by the direct relationship between extreme temperature indices and seasonal large-scale predictors during 19612008. Next, we took the second year (1961) for prediction and the remaining 48 values for the fitting of the model. This process was repeated until all the years were used once in the prediction and validation of the models. In that way, 49 models were made and the same number of predictions was carried out. The correlation coefficient $(R)$, root mean square error (RMSE) and mean absolute error (MAE) of the predictions and observations were used as skill scores to quantify the model skill.
To obtain the downscaled extreme indices from the GCM, the established statistical downscaling models of DS2 were applied to the HadCM3 historical simulation and RCP4.5 scenario, in order to simulate historical and future extreme temperature indices during 1960-2035 at the selected stations. Because of the difference between the HadCM3 historical simulation and the NCEP-NCAR Reanalysis data, the predictor data from the HadCM3 output could not be directly applied to the DS2 models established by the NCEP-NCAR Reanalysis data. Thus, some preprocessing was needed. Firstly, the HadCM3 simulations of H850 and T850 were standardized, with respect to the period 1980-99, and then interpolated to the grids of the NCEP-NCAR Reanalysis data. This procedure ensured that the results downscaled from the HadCM3 outputs were not affected by the bias in the HadCM3 simulation. Secondly, the standardized fields of H850 and T850 were spatially combined into a new field $(H+T)$ with the number of grids being equal to the sum of both H850 and T850, which was similar to the treatment for the NCEP-NCAR Reanalysis data.

In order to ensure consistency between the HadCM3-simulated EOFs and those from the NCEPNCAR Reanalysis data, the common EOF method was carried out to obtain the common EOFs of $H+T$ from

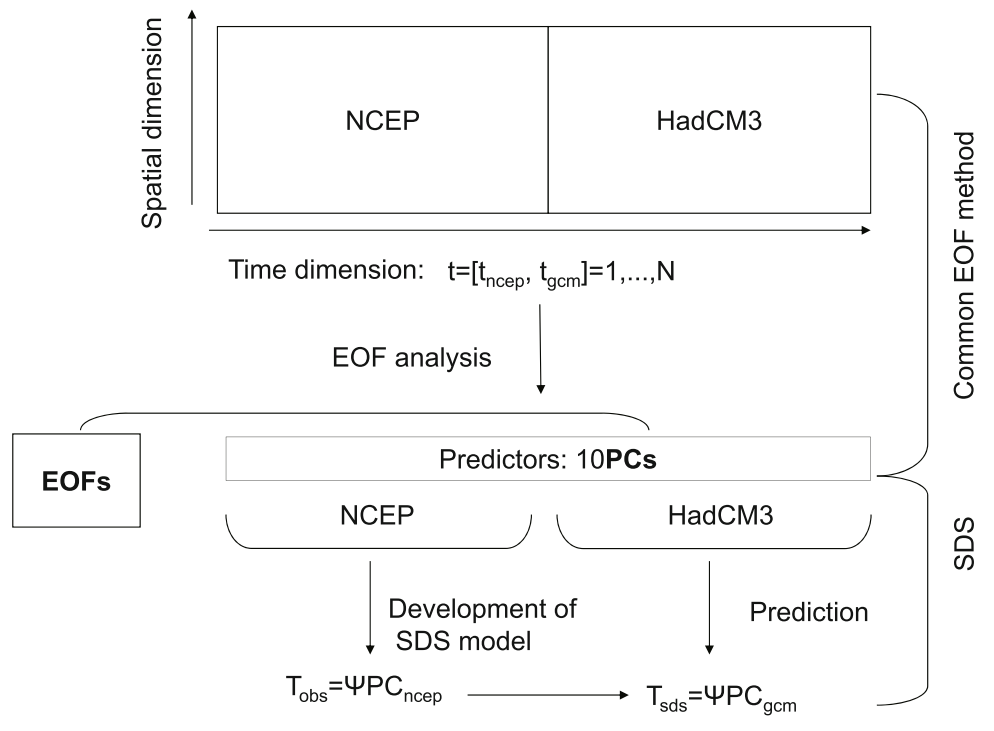

Fig. 2. Illustration of the statistical downscaling process using common EOF analysis. Here, $t_{\mathrm{ncep}}$ and $t_{\mathrm{gcm}}$ denote time dimensions taken from NCEP-NCAR Reanalysis data and HadCM3 output, respectively, and $t$ is the time dimension of the combined dataset between the two. The corresponding PCs from NCEP-NCAR $\left(\mathrm{PC}_{\text {ncep }}\right)$ and observations $\left(T_{\text {obs }}\right)$ at selected stations were used for model calibration and the matrix of the regression coefficients is indicated by $\Psi$. $\mathrm{PC}_{\mathrm{gcm}}$ (corresponding to HadCM3) were used for prediction. Finally, the estimated results $\left(T_{\mathrm{sds}}\right)$ were obtained by using the statistical downscaling method (SDS). 
these two sources (Benestad, 2001). Figure 2 illustrates how the common EOF analysis is performed and how the common EOF products were used for downscaling. The principle of the common EOF method is that two fields $(H+T$ from NCEP-NCAR and HadCM3) with data points on common grids were combined along the time axis, and EOF analysis was applied to the combined dataset (Benestad, 2001). The common EOFs derived from the EOF analysis represent the same spatial patterns between NCEPNCAR Reanalysis data and HadCM3 simulations, whereas the PCs from NCEP-NCAR and HadCM3 represent changes in common EOFs with time. In this study, the first ten PCs derived from NCEPNCAR Reanalysis and station observations were used for the calibration of the statistical downscaling models, whereas corresponding PCs from the HadCM3 simulations were used to simulate historical and future scenarios of extreme temperature indices. Finally, the results of the statistical downscaling models were inflated by firstly multiplying the inverse of their standard deviations relative to the period 1980-99 and then de-standardizing them by by multiplying their observed standard deviations and adding their mean relative to the period $1980-99$. This made it possible to keep the downscaled variance to the same level in the observation.

\section{Results}

\subsection{Correlation between the means and vari- ances in temperature and percentile-based indices}

Changes in the mean and variance of temperature are considered as two main sources that have impacts on changes in extreme temperature events (Katz and Brown, 1992; Griffiths et al., 2005). In general, the distribution of temperatures approximates a normal distribution. Change in mean temperature will impact

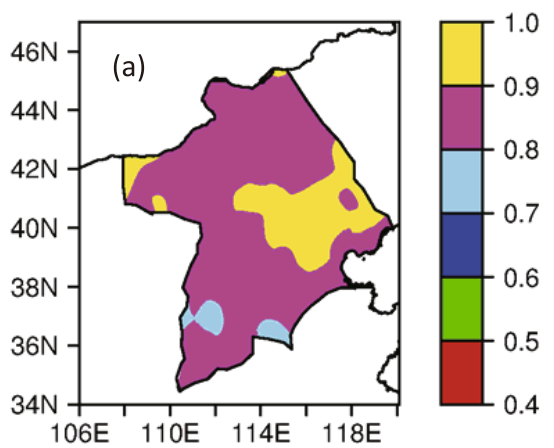

on extremes as the only source, if there is no change in variance. However, the relationship will become complex if variance also changes (Fu et al., 2008). Therefore, the associations between these two main sources and percentile-based indices should be calculated in order to explore the feasibility of DS2, where change in the mean state was used as the only predictor for percentile-based indices, without taking variance into consideration. In this study, the mean (Tmaxave and Tminave) and variance (Tmaxsd and Tminsd) in daily Tmax and Tmin series were used to indirectly explain the relationship between the mean state and extremes, although large-scale seasonal mean variables were used as the predictors rather than Tmaxave or Tminave itself.

Strong relationships were found between Tmaxave and Tmax90p with $R$ values greater than 0.8 at most stations (Fig. 3a). The relationship between Tminave and Tmin $10 \mathrm{p}$ was also very strong, with $R$ values greater than 0.7 at most stations, though the $R$ values were slightly weaker than those of Tmax in southern parts (Fig. 3b). However, the $R$ values between Tmaxsd and Tmax90p were mostly lower than 0.6 (Fig. 4a), and those between Tminsd and Tmin10p had negative correlation coefficients, mostly ranging between -0.6 and -0.5 (Fig. $4 \mathrm{~b}$ ). The stronger correlations between the mean temperature and percentilebased indices indicate that change in the mean temperature is a more important predictor of changes in percentile-based indices than those in variance for summer temperature in northern China. Therefore, these findings support the application of DS2 in which percentile-based indices are related to seasonal mean large-scale predictors.

\subsection{Validation of statistical downscaling mod- els}

To illustrate the relative merit of the two modeling approaches DS1 and DS2, data from Beijing station

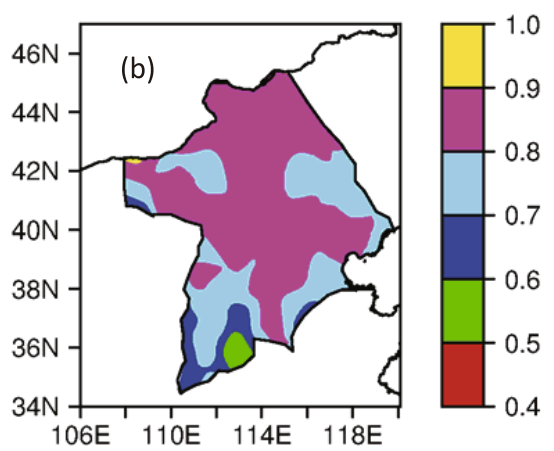

Fig. 3. Correlation between mean temperatures and percentile-based indices: (a) Tmaxave and Tmax90p; (b) Tminave and Tmin10p. 

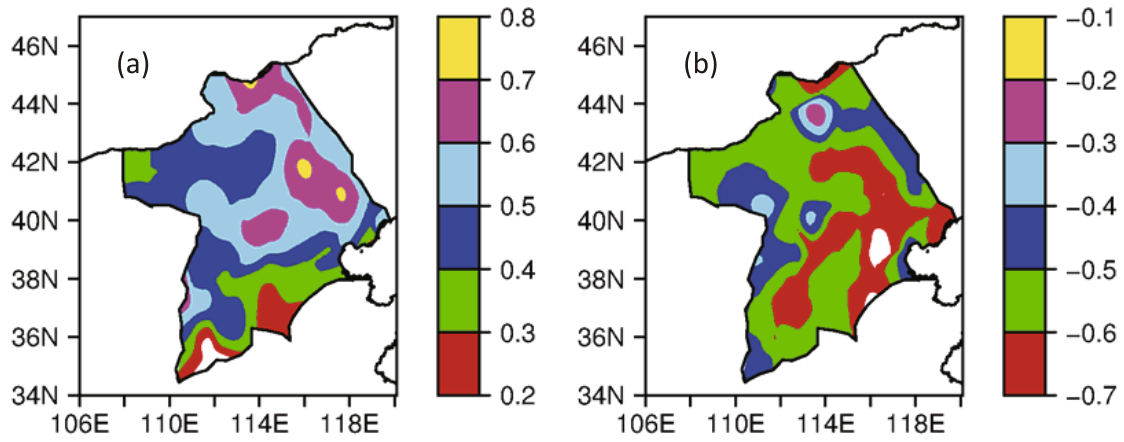

Fig. 4. Correlation between standard deviations and percentile-based indices: (a) Tmaxsd and Tmax90p; (b) Tminsd and Tmin10p.

were used to construct and validate the downscaling models. The four extreme indices downscaled by DS1 and DS2 through the cross-validation procedure were compared with observation data from Beijing for 19602008 and the results are shown in Fig. 5. For Tmaxave, both the DS1 and DS2 simulations agreed well with observations, with DS2 slightly superior to DS1 (Fig. 5a), while for Tmax90p the results from DS2 were significantly better than those of DS1 (Fig. 5b). In the case of Tminave, both DS1 and DS2 estimates showed a very close relationship with the observation (Fig. 5c), whereas the result of DS2 for Tmin10p was much closer to the observation than that of DS1 (Fig. 5d). The three skill scores between the four downscaled indices using DS1 and DS2 were computed and the results are shown in Table 1. For Tmaxave, the model performance of DS2 showed an obvious superiority to that of DS1 according to all the three skill scores. For
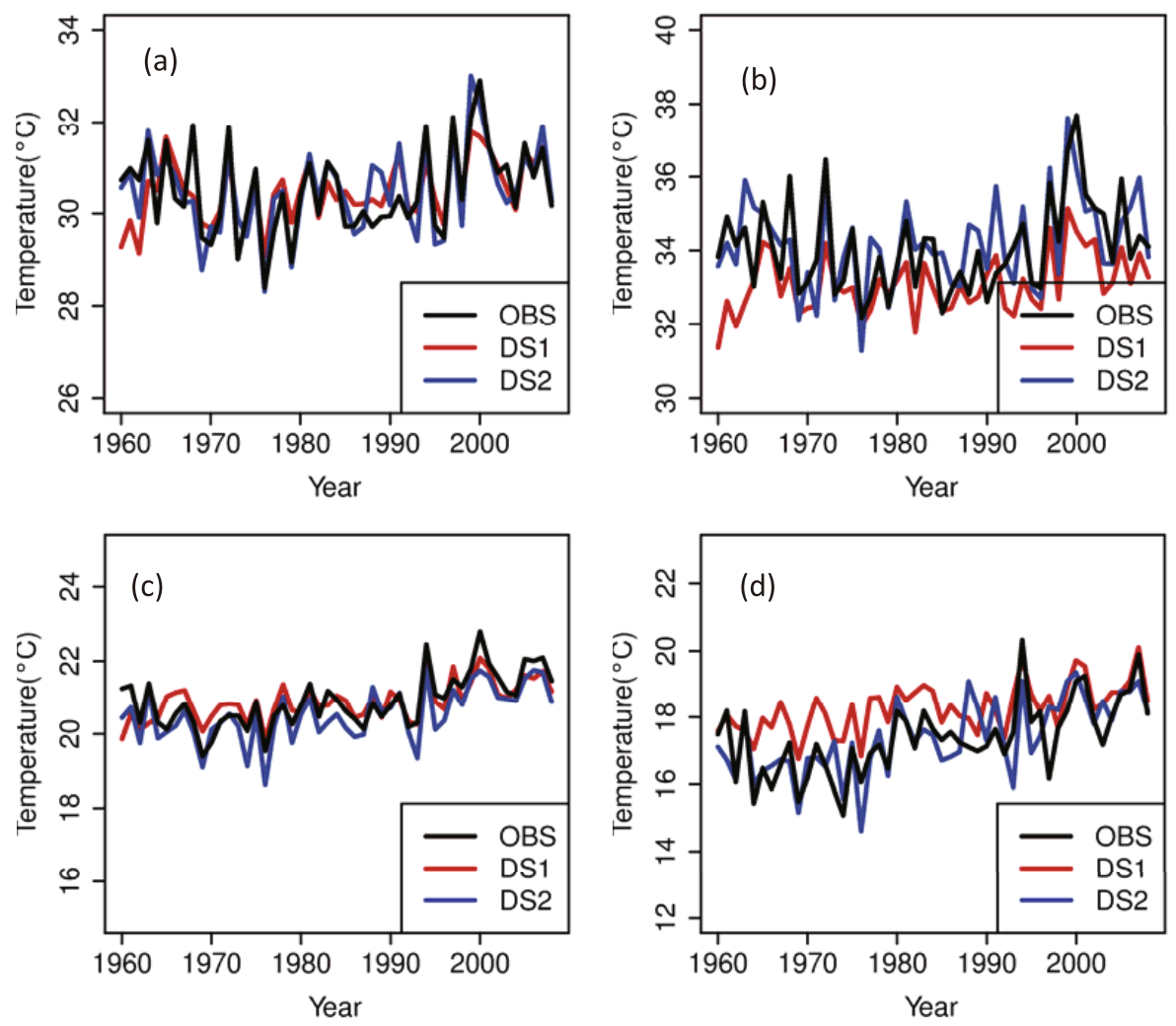

Fig. 5. Downscaled time series of the four indices of temperature extremes by DS1 and DS2 within the cross-validation procedure at Beijing Station: (a) Tmaxave; (b) Tmax90p; (c) Tminave; and (d) Tmin10p. 
Table 1. Validation performance of the four extreme temperature indices at Beijing station within the cross-validation procedure using DS1 and DS2.

\begin{tabular}{cccccc}
\hline Index & & Tmaxave & Tmax90p & Tminave & Tmin10p \\
\hline \multirow{3}{*}{ DS1 } & RMSE & 0.64 & 1.31 & 0.45 & 0.77 \\
& R & 0.72 & 0.70 & 0.36 & 0.79 \\
\multirow{2}{*}{ DS2 } & MAE & 0.5 & 1.06 & 0.49 & 0.95 \\
& RMSE & 0.57 & 0.96 & 0.89 & 0.79 \\
& R & 0.81 & 0.68 & 0.41 & 0.73 \\
\hline
\end{tabular}

Tmax90p, compared to DS1, although DS2 did not improved the modeling skill in terms of $R$, DS2 showed much better performance in terms of RMSE and MAE. In the case of Tminave, the model performance of DS2 exceeded that of DS1 in terms of $R$, while DS2 showed no obvious superiority to DS1 in terms of RMSE and MAE. Compared to DS1, DS2 showed better performance in downscaling Tmin10p in terms of RMSE and MAE, although no obvious improvement in terms of the $R$ value was found. Overall, it can be concluded that the model performance of DS2 was obviously better than that of DS1, especially for percentilerelated indices (Tmax90p and Tmin $10 \mathrm{p}$ ), according to the comprehensive comparison of the two approaches. Therefore, in what followed, only DS2 was used.

The model performance of DS2 was checked at all

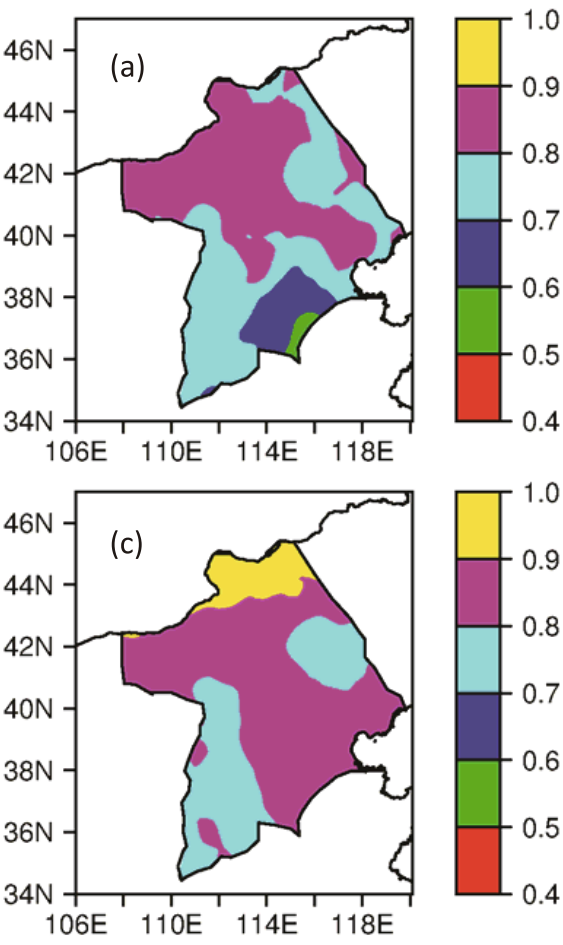

the 48 stations for the four extreme indices. Figure 6 shows the spatial distribution of the $R$ values of the four extreme temperature indices between the observed and the downscaled data using DS2. For Tmaxave (Fig. 6a) and Tminave (Fig. 6c), the $R$ values at most stations were more than 0.8 , while those of Tmax90p (Fig. 6b) and Tmin10p (Fig.6d) ranged between 0.6 and 0.7 in most areas, with the exception of the southern part of the study area. With these results, we can conclude that the DS2 simulations of the four indices produced a satisfactory performance, especially for both Tmaxave and Tminave.

When DS2 was applied to HadCM3 simulations, the PCs corresponding to NCEP-NCAR data obtained by the common EOF method of HadCM3 and NCEPNCAR predictors were used to establish the statis-

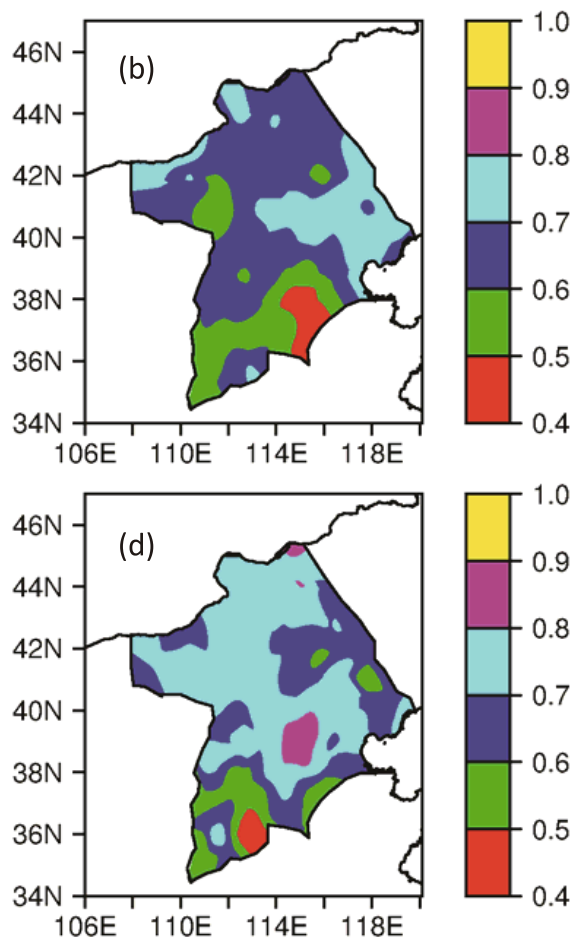

Fig. 6. Spatial distribution of correlation coefficients of the four extreme temperature indices between observed and downscaled results using DS2 within the cross-validation procedure: (a) Tmaxave; (b) Tmax90p; (c) Tminave; and (d) Tmin10p. 

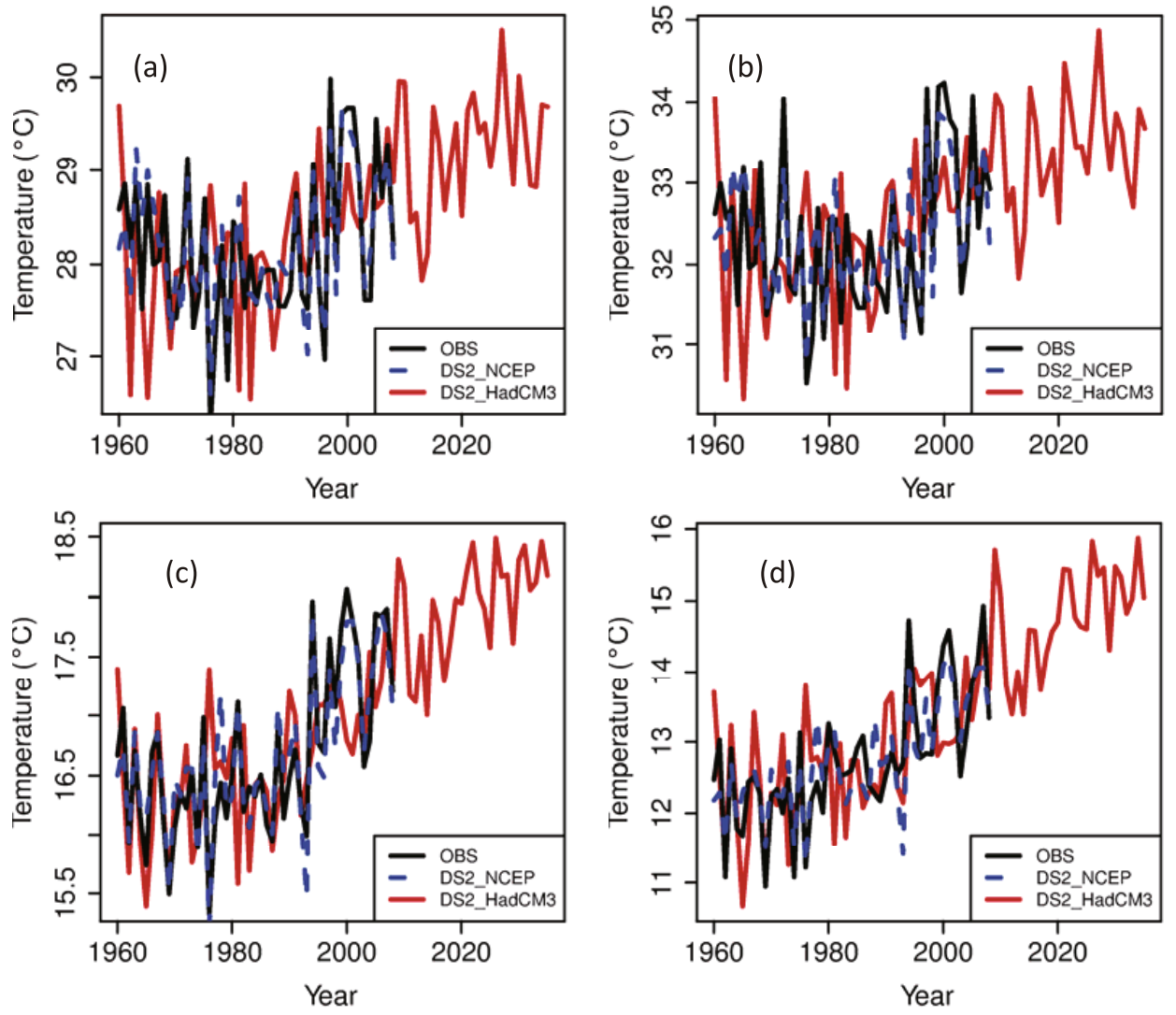

Fig. 7. Time series of the four extreme temperature indices averaged over northern China where OBS indicates the observations; DS2_NCEP indicates the downscaled results from DS2 by using the PCs of common EOFs corresponding to NCEP-NCAR data; DS2_HadCM3 indicates the downscaled ones from DS2 by using the PCs of common EOFs corresponding to HadCM3 simulations. (a) Tmaxave; (b) Tmax90p; (c) Tminave; (d) Tmin10p.

tical downscaling models, rather than those by EOF analysis of only NCEP-NCAR predictors. Thus, the model performance of DS2 based on the results of the common EOF analysis was also checked and the results are shown in Fig. 7. The regional means of the four extreme temperature indices in northern China based on the observations are indicated by black lines and the downscaled ones using the PCs corresponding to NCEP-NCAR data are shown as blue dotted lines in each of the panels in Fig. 7. It can be seen from Fig. 7 that DS2 was able to successfully estimate the trends in the two Tmax-related indices (Tmaxave and Tmax90p), which indicate decreases before 1980 and obvious increases after 1980 (Figs. 7a and b), and also successfully simulate significant warming trends since 1960 in two Tmin-related indices (Tminave and Tmin10p), similar to the observations (Figs. 7c and d). The conclusion can be made that the established models based on common EOF analysis possess reasonable skill for the four indices. As a result, they can be further applied to the HadCM3 simulations.

\subsection{Downscaling of HadCM3 output}

The statistical downscaling models established between the PCs corresponding to the NCEP-NCAR predictors and the historical four indices were applied to those corresponding to the HadCM3 output, and the historical and future simulations of the four indices were estimated at each station. The regional means of the four downscaled indices using the HadCM3 output are shown by red lines in Fig. 7. The historical simulations agreed well with the observations for each index. For the prediction of future scenarios, the regional averages of the four extreme indices were found to have a significant increase up to 2035. For example, Tmaxave increased from about $28^{\circ} \mathrm{C}$ to about $30^{\circ} \mathrm{C}$ (Fig. 7a) and Tmax90p from about $32^{\circ} \mathrm{C}$ to around $34^{\circ} \mathrm{C}$ (Fig. 7b); Tminave increased from $16.5^{\circ} \mathrm{C}$ to $18^{\circ} \mathrm{C}$ (Fig. $7 \mathrm{c}$ ) and Tmin $10 \mathrm{p}$ from $12^{\circ} \mathrm{C}$ to about $15^{\circ} \mathrm{C}$ (Fig. $7 \mathrm{~d}$ ). The 20 year averages (2016-35) of the four extreme indices were compared with the 1980-99 average. Two Tmaxrelated indices (Tmaxave and Tmax90p) had an av- 

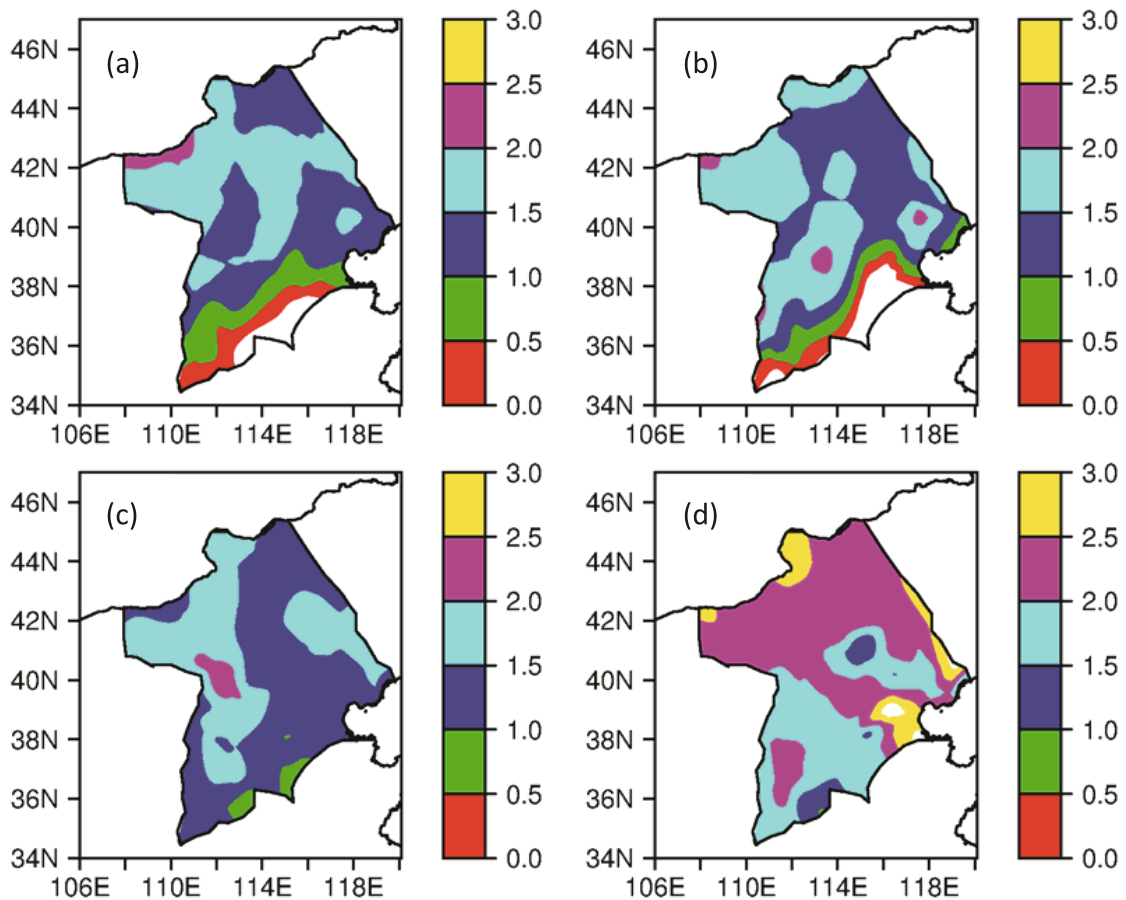

Fig. 8. Change in the 20-year averages (2016-35) of extreme temperature indices downscaled by DS2, relative to the 1980-99 mean: (a) Tmaxave; (b) Tmax90p; (c) Tminave; and (d) Tmin10p.

erage warming of around $1.5^{\circ} \mathrm{C}$ at most stations, except the southern part of northern China (Figs. 8a and b), and Tminave had an average warming of around $1.0^{\circ} \mathrm{C}$ (Fig. $8 \mathrm{c}$ ). Compared to the three extreme indices above, Tmin10p had a more notable warming trend of around $2{ }^{\circ} \mathrm{C}$ at most sites, except the southern part of northern China where there was a rise of about $1.5^{\circ} \mathrm{C}$ (Fig. $8 \mathrm{~d}$ ).

\section{Discussion and conclusions}

A strong relationship between summer mean temperature and percentile-based temperature indices and a weak relationship between variance in temperature and percentile-based temperature indices were found in northern China, indicating that changes in mean temperature have a major impact on changes in the percentile-based indices. Griffiths et al. (2005) also considered that strong correlations between mean temperature and extreme indices in the Asia-Pacific region support the hypothesis that changes in mean temperature may be used to predict changes in extreme climate. Thus, these results provide a strong basis to connect extreme indices with mean large-scale predictors in northern China.

A comparison between the two statistical downscaling approaches (DS1 and DS2) was made in downscaling four indices of temperature extremes at Bei- jing station. It can be concluded that the DS2 models, which are based on relationships between seasonal large-scale predictors and extreme temperature indices, are superior to those using daily values (DS1) of local temperature and large- scale predictors.

By applying DS2 to downscale extreme temperature indices at 48 stations in northern China, the results of cross-validation showed that extreme temperature indices have a strong correlation with seasonal large-scale climate in summer, which confirms the relative merit of DS2 over DS1. Moreover, DS2 needs monthly GCM outputs, which are more easily available than daily ones. Thus, DS2 is considered useful in solving the difficult and complex problem of downscaling daily Tmax and Tmin. To summarize, DS2 has been shown to be an effective approach for downscaling extreme temperature indices based on percentiles.

This study focused on solving the problem of downscaling statistics such as the 90th percentile of daily Tmax and 10th percentile of daily Tmin, rather than the daily time series of temperatures, which is similar to previous work by Benestad (2009) and Hass and Born (2011). Benestad (2009) successfully used statistical downscaling to directly predict the probability density function of precipitation in Oslo, and Hass and Born (2011) applied probability downscaling to downscale the 25 th, 50 th and 75 th percentiles of precipitation in a subtropical mountainous area. Both studies 
were aimed at statistically downscaling the distribution function in which it should be assumed that precipitation obeys a certain distribution and the parameters of the cumulative distribution function or probability density function are to be directly downscaled, rather than downscaling daily precipitation time series themselves. In contrast to the studies above, this study focused on the statistical downscaling of the statistics of daily time series, such as the 90th percentile of Tmax and 10th percentile of Tmin, which has one major advantage in that the statistical downscaling processes do not need to make the assumption that daily time series follow a certain distribution.

This study, and the study of Hass and Born (2011), used the linear regression method, which is valid when the variables involved approximately obey the normal distribution. The performance of directly applying the linear regression method to extreme temperature indices was superior to that of directly using daily data, enabling us to conclude that linear regression models are probably appropriate for downscaling percentilebased indices.

As we know, statistical downscaling results have some uncertainties (Chen et al., 2006). This work focused on comparing two statistical downscaling approaches. In fact, there are other aspects that can be important too. As an example, different predictor domains and various different combinations of possible predictors can be explored. In addition, this work used only one global climate model and one emission scenario to project future changes, knowing that other models and scenarios will give different results. Nevertheless, the findings of this study will be useful for more systematic studies in the future.

Acknowledgements. This work was jointly sponsored by the National Basic Research Program of China "973" Program (Grant No. 2012CB956200), the Knowledge Innovation Project (Grant No. KZCX2-EW-202) and the Strategic Priority Research Program (Grant No. XDA05090103) of the Chinese Academy of Sciences.

\section{REFERENCES}

Achberger, C., M.-L. Linderson, and D. Chen, 2003: Performance of the Rossby centre regional atmospheric model in southern Sweden: Comparison of simulated and observed. Theor. Appl. Climatol., 76, 219-234.

Benestad, R. E., 2001: A comparison between two empirical downscaling strategies. Int. J. Climatol., 21, $1645-1668$

Benestad, R. E., 2009: Downscaling precipitation extremes: Correction of analogy model through PDF predictions. Theor. Appl. Climatol., 100, 1-21.

Benestad, R. E., I. Hanssen-Bauer, and D. Chen, 2008:
Empirical-Statistical Downscaling. World Scientific Publishing Co. Pte. Ltd., Singapore, 228pp.

Bretherton, C. S., C. Smith, and J. M. Wallace, 1992: An intercomparison of methods for finding coupled patterns in climate data. J. Climate, 5, 541-560.

Chambers, J. M., and T. J. Hastie, 1992: Statistical Models in S. Wadsworth and Brook/cole, Pacific grove, California, 608pp.

Chen, D., C. Achberger, J. Raisanen, and C. Hellstrom, 2006: Using statistical downscaling to quantify the GCM-related uncertainty in regional climate change scenarios: A case study of Swedish precipitation. Adv. Atmos. Sci., 23(1), 54-60.

Chen, D., C. Achberger, U. Postgård, A. Walther, Y. Liao, and T. Ou, 2008: Using a weather generator to create future daily precipitation scenarios for Swed. Res. Rep. C76, Earth Sciences Centre, University of Gothenburg, Gothenburg, Sweden, 82pp.

Coulibaly, P., 2004: Downscaling daily extreme temperature with genetic programming. Geophys. Res. Lett., 31, L16203, doi: 10.1029/2004GL020075.

Fan, L., 2009: Statistical downscaled temperature scenarios over China. Atmos. Oceanic Sci. Lett., 2(4), 408-213.

Fan, L., 2010: Preliminary study of statistically downscaled temperature ensemble predictions in eastern China. Plateau Meteorology, 29(2), 392-402. (in Chinese)

Fan, L., C. Fu, and D. Chen, 2005: Review on creating future climate change scenarios by statistical downscaling techniques. Advances in Earth Science., 20(3), 320-329. (in Chinese)

Fan, L., C. Fu, and D. Chen, 2007: Estimation of local temperature change scenarios in North China using statistical downscaling method. Chinese J. Atmos. Sci., 31(5), 887-897. (in Chinese)

Fan, L. J, C. B. Fu, and D. L. Chen, 2011: Long-term trend of temperature derived by statistical downscaling based on EOF analysis. Acta Meteorologica Sinica, 25(3), 327-339, doi: 10.1007/s13351-0110308-0.

Fu, C., Z. Jiang, Z. Guan, J. He, and Z. Xu, 2008: Regional Climate Studies of China. Springer, 476pp.

Gordon, C., C. Cooper, C. A. Senior, H. Banks, J. M. Gregory, T. C. Johns, J. F. B. Mitchell, and R. A. Wood, 2000: The simulation of SST, sea ice extents and ocean heat transports in a version of the Hadley Centre coupled model without flux adjustments. Climate Dyn., 16, 147-168, doi: 10.1007/s003820050010.

Griffiths, G. M., and Coauthors, 2005: Change in mean temperature as a predictor of extreme temperature change in the Asia-Pacific region. Int. J. Climatol., 25, 1301-1330.

Hanssen-Bauer, I., E. J. Forland, J. E. Haugen, and O. E. Tveito, 2003: Temperature and precipitation scenarios for Norway: Comparison of results from dynamical and statistical downscaling. Climate Research, 25, 15-23.

Hanssen-Bauer, I., C. Achberger, R. E. Benestad, D. 
Chen, and E. Forland, 2005: Statistical downscaling of climate scenarios over Scandinavia: A review. Climate Research, 29, 255-268.

Hass, R., and K. Born, 2011: Probabilistic downscaling of precipitation data in a subtropical mountain area: A two-step approach. Nonlinear Processes in Geophysis., 18, 223-234.

Hellström, C., and D. Chen, 2003: Statistical downscaling based on dynamical downscaled predictors: application to monthly precipitation in Sweden. Adv. Atmos. Sci., 20(6), 951-958.

Hellström, C., D. Chen, C. Achberger, and J. Räissänen, 2001: A comparison of climate change scenarios for Sweden based on statistical and dynamical downscaling of monthly precipitation. Climate Research, 19, $45-55$.

Hundecha, Y., and A. Bardossy, 2008: Statistical downscaling of extremes of daily precipitation and temperature and construction of their future scenarios. Int. J. Climatol., 28, 589-610.

Huth, R., 2002: Statistical downscaling of daily temperature in central Europe. J. Climate, 15, 1731-1743.

IPCC, 2007: Climate Change 200\%: The Physical Science Basis. Contribution of the Working Group I to the Fourth Assessment Report of the Intergovernmental Panel on Climate Change, S. Solomon et al., Eds., Cambridge University Press, Cambridge, United Kingdom and New York, NY, USA, 996pp.

Jones, P. D., E. B. Horton, C. K. Folland, M. Hulme, D. E. Parker, and T. A. Basnett, 1999: The use of indices to identify changes in climatic extremes. $\mathrm{Cli}$ matic Change, 42, 131-149.

Kalnay, E., and Coauthors, 1996: The NCEP-NCAR 40year reanalysis project. Bull. Amer. Meteor. Soc., 77(3), 437-471.

Katz, R. W., and B. G. Brown, 1992: Extreme events in a changing climate: Variability is more important than averages. Climatic Change, 21(3), 289-302.

Lee, T. C., K. Chan, and W. Ginn, 2011a: Projection of extreme temperature in Hongkong in the 21st Century. Acta Meteorologica Sinica, 25(1), 1-20, doi: 10.1007/s13351-011-0001-3.

Lee, T. C., H. S. Chan, E. W. L. Ginn, and M. C. Wong, 2011b: Long-term trends in extreme temperatures in Hong Kong and southern China. Adv. Atmos. Sci., 28(1), 147-157, doi: 10.1007/s00376-010-9160-x.

Li, Z., and Z. Yan, 2009: Homogenized China daily mean/maximum/minimum temperature series 19602008. Atmos. Oceanic Sci. Lett., 2(4), 237-243.
Liu, Y., K. Fan, and H. Wang, 2011: Statistical downscaling prediction of summer precipitation in Southeastern China. Atmos. Oceanic Sci. Lett., 4(3), 173-180.

Moss, R., and Coauthors, 2008: Towards new scenarios for analysis of emissions, climate change, impacts, and response strategies. Intergovernmental Panel on Climate Change, Geneva, 132pp.

Moss, R. H., and Coauthors, 2010: The next generation of scenarios for climate change research and assessment. Nature, 463, 747-756, doi: 10,1038/nature08823.

Pope, V. D., M. L. Gallani, P. R. Rowntree, and R. A. Stratton, 2000: The impact of new physical parameterizations in the Hadley centre climate model-HadAM3. Climate Dyn., 16, 123-146, doi: $10.1007 / \mathrm{s} 003820050009$.

Taylor, K., R. J. Stouffer, and G. A. Meehl, cited 2009: A summary of the CMIP5 Experiment Design. [Available online at http://cmip-pcmdi.llnl.gov/cmip5/ docs/Taylor_CMIP5_design.pdf.]

Thomson, A. M., and Coauthors, 2011: RCP4.5: A pathway for stabilization of radiative forcing by 2100 . Climatic Change, 109, 77-94, doi: 10.1007/s10584-0110151-4.

von Storch, H., and F. W. Zwiers, 1999: Statistical Analysis in Climate Research. Cambridge University Press, 496pp.

Wetterhall, F., A. Bárdossy, D. Chen, S. Halldin, and C. $\mathrm{Y}$. Xu, 2006: Daily precipitation-downscaling techniques in three Chinese regions. Water Res., 42(11), w11423, doi: 10.1029/2005WR004573.

Wilks, D. S., 2010: Use of stochastic weather generators for precipitation downscaling WIREs. Climatic Change, 1(6), 898-907, doi: 10.1002/wcc.85.

Yan, Z., and C. Yang, 2000: Geographic patterns of extreme climate changes in China during 1951-97. Climatic Environ. Res., 5(3), 265-270. (in Chinese)

Yan, Z., and Coauthors, 2002: Trends of extreme temperatures in Europe and China based on daily observations. Climatic Change, 53(1-3), 355-392.

Zhao, F., and Z. Xu, 2008: Statistical downscaling of future temperature change in source of the Yellow River Basin. Plateau Meteorology, 27(1), 153-161. (in Chinese)

Zhu, C., C. Park, W. Lee, and W. Yun, 2008: Statistical downscaling for multi-model ensemble prediction of summer monsoon rainfall in the Asia-pacific region using geopotential height field. Adv. Atmos. Sci., 25(5), 867-884, doi: 10.1007/s00376-008-0867-x. 